\title{
Development Status and Thinking of Passive Building in the Yangtze River Delta Region
}

\author{
Weicheng Shang ${ }^{1}$, Bojun Wang ${ }^{2 *}$, and Yanping Yang ${ }^{1}$ \\ ${ }^{1}$ School of Civil Engineering and Architecture, Jiangsu University of Science \&Technology, Zhenjiang, Jiangsu Province, 212100 , \\ China \\ ${ }^{2}$ College of Zhangjiagang, Jangsu University of Science and Technology, Suzhou, Jiangsu Province, 215600, China
}

\begin{abstract}
Passive building is a kind of building that can use natural way to reduce energy consumption on the premise of satisfying indoor comfort. The characteristics of energy saving and emission reduction can solve the problem of energy shortage, which is the future development trend of buildings in the Yangtze River Delta region. However, the popularization of passive architecture in the Yangtze River Delta region is relatively slow in recent years. This paper analyzes its development status and influencing factors, and puts forward some suggestions to provide some reference for promoting the explosive development of passive buildings in the Yangtze River Delta region.
\end{abstract}

\section{Introduction}

With the development of China's economy and the continuous improvement of people's living standards, energy and environmental issues have been increasingly concerned. Research Report on China's building energy consumption (2019) describes the proportion of China's building energy consumption. China's total building energy consumption is 947 million tons of standard coal, accounting for $21.11 \%$ of the national energy consumption, as shown in Figure 1 [1]. In addition, according to the statistics of Energy Consumption Statistics Committee of China Building Energy Efficiency Association, the center of spatial change of building energy consumption begins to move southward. Because of its extensive economic development mode, the energy utilization rate in the Yangtze River Delta has been in a low state. Taking 2016 as an example, the annual energy consumption in the Yangtze River Delta region increased by 3.69 times compared with 1995, with an average annual growth rate of $6.74 \%$, higher than the national total energy consumption growth rate of $6.12 \%$ [2]. Among them, the energy consumption in the construction industry is 5.07 million tons of standard coal, accounting for $2.04 \%$ of the total energy consumption change [2]. At present, the only way to realize sustainable development of the Yangtze River Delta region is to develop passive buildings and further reduce the energy consumption of construction industry.

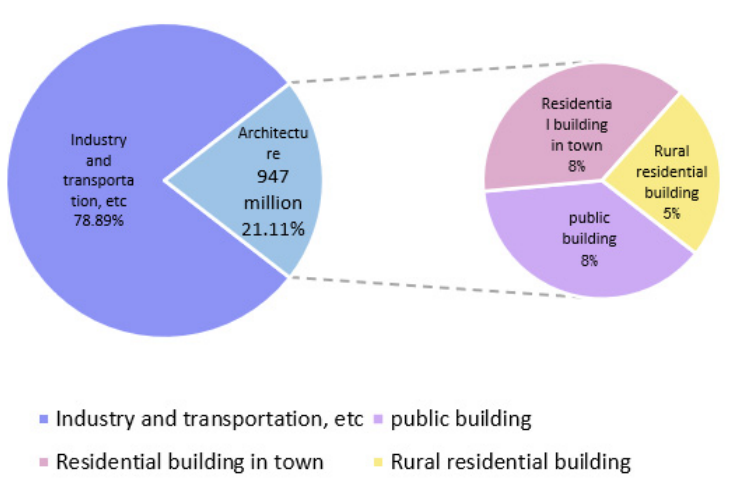

Figure 1. The proportion of building energy consumption in China.

\section{Development status of passive buildings in the Yangtze River Delta region}

\subsection{Relevant policies}

As shown in Table 1, in order to accelerate the development of passive buildings and improve energy efficiency, the Yangtze River Delta region has issued the following policies on passive buildings.

\footnotetext{
$\overline{\text { * Corresponding author: wangbj@just.edu.cn }}$
} 
Table 1. Examples of passive building policies in the Yangtze River Delta region

\begin{tabular}{|c|c|c|}
\hline Region & Release Time & Policy \\
\hline \multirow{5}{*}{ Shanghai } & 2019.3 .13 & $\begin{array}{l}\text { "Technical Guidelines for Ultra-low Energy } \\
\text { Consumption Buildings in Shanghai (Trial)" }\end{array}$ \\
\hline & 2019.3 .20 & $\begin{array}{l}\text { "Notice on Printing and Distributing the Task } \\
\text { Decomposition Objectives of Building Energy } \\
\text { Conservation Work of All Districts and } \\
\text { Related Entrusted Management Units in 2019" }\end{array}$ \\
\hline & 2020.3 .20 & $\begin{array}{l}\text { "Special Support Measures for Building Energy } \\
\text { Conservation and Green Building } \\
\text { Demonstration Projects in Shanghai" }\end{array}$ \\
\hline & 2020.4 .24 & $\begin{array}{l}\text { "Shanghai Green Building Management } \\
\text { Measures (Draft)" }\end{array}$ \\
\hline & 2020.7 .28 & $\begin{array}{l}\text { "Guidelines for Declaration of Special Support } \\
\text { Funds for Building Energy Conservation and } \\
\text { Green Building Demonstration Projects in } \\
\text { Shanghai" }\end{array}$ \\
\hline \multirow{3}{*}{$\begin{array}{l}\text { Jiangsu } \\
\text { Province }\end{array}$} & 2019.4 .24 & $\begin{array}{l}\text { "Technical Guidelines for Ultra-low Energy } \\
\text { Consumption Residential Buildings in Jiangsu } \\
\text { Province (Draft for Comments)" }\end{array}$ \\
\hline & 2019.11 .18 & $\begin{array}{l}\text { "Notice on Organizing and Applying for } 2020 \\
\text { Jiangsu Provincial Energy Conservation and } \\
\text { Emission Reduction (Building Energy } \\
\text { Conservation) Special Fund Award and } \\
\text { Subsidizing Project" }\end{array}$ \\
\hline & 2020.3 .27 & $\begin{array}{l}\text { "Opinions of the Provincial Government on } \\
\text { Promoting the Development of Green } \\
\text { Industry" }\end{array}$ \\
\hline
\end{tabular}

\subsection{Engineering practices}

\subsection{1 "Hamburg House"}

At the 2010 Shanghai World Expo, the Hamburg House was the first passive house in China, which integrates environmental protection technology, residential and commercial functions. This passive building is selfsufficient by absorbing clean energy sources such as solar and geothermal. Its heating demand is less than 15 $\mathrm{kwh} / \mathrm{m}^{2} \mathrm{a}$ and primary energy consumption is less than 50 $\mathrm{kwh} / \mathrm{m}^{2} \mathrm{a}$. "Hamburg House" makes people begin to understand passive architecture, and lays the foundation for the development of passive architecture in the Yangtze River Delta region [3].

\subsubsection{Jiangsu Provincial Building Energy Conservation and Green Building R\&D Building}

Located in Qixia District of Nanjing, Jiangsu Provincial Building Energy Conservation and Green Building R\&D Building is a typical passive office building, covering an area of $19100 \mathrm{~m}^{2}$ and a total construction area of 23100 $\mathrm{m}^{2}$. Combined with the climatic characteristics of hot summer and cold winter in the Yangtze River Delta Region, this project adopts a variety of green building technologies such as soil source heat pump, water storage, solar thermal and so on [4]. The project provides experience and data for exploring the passive building technology strategies adapted to the Yangtze River Delta region and revising the local building energy efficiency standards.

These projects provide experience and data for exploring the passive building technology strategies adapted to the Yangtze River Delta region and revising the local building energy efficiency standards.

\section{Factors affecting the development of passive buildings in the Yangtze River Delta region}

\subsection{Advantageous factors}

\author{
3.1.1 Passive buildings can save energy and \\ reduce emissions, which is in line with the \\ sustainable development concept of the \\ construction industry in the Yangtze River Delta \\ region
}

The Yangtze River Delta region is an important part of the middle and lower reaches of the Yangtze River Plain. Affected by the subtropical monsoon climate, most cities are hot and rainy in summer and cold and humid in winter. Therefore, residents need to use a lot of air conditioning, cooling in summer, heating in winter and dehumidification all year round. Passive buildings have the characteristics of constant temperature, constant oxygen and humidity, which can not only greatly reduce the use of air conditioning, promote energy conservation and emission reduction, reduce environmental damage and pressure, but also improve indoor living comfort.

\subsubsection{Passive buildings can save energy and reduce emissions, which is in line with the sustainable development concept of the construction industry in the Yangtze River Delta region}

Due to its high population density and strong innovation ability, the industry and commerce in the Yangtze River Delta region are well developed, and its economic development level is leading in the country. With the advantage of economic development, the region occupies an important strategic position in the overall modernization construction of the country. The implementation of passive buildings in the Yangtze River Delta can solve the problem of insufficient energy supply, accelerate the pace of industrial modernization, and promote its high-quality and integrated development. At the same time, it can also play an exemplary reference role for the development of passive buildings in the later developing areas. Although the strict construction details and high-performance materials and equipment make the cost per square meter of passive buildings slightly higher than that of ordinary buildings, the costs of heating, cooling and dehumidification can be greatly saved by virtue of its energy saving and emission reduction characteristics during the use of the building [5]. In addition, the service life of passive buildings is longer than normal buildings. All in all, passive building is an economical and environmentally friendly option for its occupants. 


\subsection{Obstructive factors}

\subsubsection{The theoretical research system of passive building is not systematic}

The theoretical research on passive building in China started late, and there is a gap between China and European countries in terms of energy efficiency standards, and the relevant standards are mostly concentrated in the cold and cold regions in the north. The climatic and market conditions in the Yangtze River Delta region are different from those in the north, so it is impossible to directly apply the technical standards of passive buildings in the north. In recent years, although the pilot work of passive building has been carried out in the Yangtze River Delta, the tracking and testing of practical data of passive building needs a certain time process, and there is no large amount of actual data to optimize the technical details of passive building.

\subsubsection{Lack of a complete passive building materials industry chain and building materials testing standards}

At present, the passive building in the Yangtze River Delta is still in its infancy. In the absence of testing standards for passive building materials, the quality of materials and components is uneven, which cannot meet the high-performance requirements of passive buildings. And there is no complete industrial chain. The components of building materials cannot be used to achieve self-sufficiency in local production, and can only rely on the international market, which greatly improve the passive building transportation cost and material cost. As a result, the total cost of construction also increases.

\subsubsection{The evaluation and supervision system of passive buildings is not perfect}

The construction industry in the Yangtze River Delta region is in the transition period from extensive to highquality development. In the process of passive building design and construction, the lack of strict quality supervision and the blind pursuit of growth rate will increase the quality risk, but also cannot promote the explosive development of passive buildings in the Yangtze River Delta region.

\subsubsection{The publicity and promotion efforts are not enough, and the incentive policies are not comprehensive}

Although passive building pilot projects have been built in Hebei, Shandong and other places, the general public is still unfamiliar with the concept of the passive building. Affected by the cost, the recognition of passive energy-saving building is not high. In the past two years, although Shanghai, Jiangsu and other places have issued relevant incentive policies for passive buildings, these incentive policies are all aimed at developers or production enterprises. And buyers and residents rarely get corresponding preferential treatment. Whether passive buildings can be promoted substantially depends on the consumers' recognition.

\section{Reflections on the development of passive buildings in the Yangtze River Delta region}

The development of passive buildings has an important impact on the construction technology, economy, society and ecological environment in the Yangtze River Delta region. Compared with the current level of building energy conservation in the Yangtze River Delta region, passive buildings have higher requirements for building energy conservation. Therefore, it is an important way to further improve building energy efficiency and promote the development of passive buildings by strengthening regional cooperation in the Yangtze River Delta region and drawing on the successful experience of passive building demonstration projects in Europe and the north of China.

In terms of the technology, the research on energysaving technology should be carried out jointly among regions to increase the depth of theoretical design. The passive building in the Yangtze River Delta region started relatively late and lacked a lot of theoretical and technical research and depth. Although there are many successful passive building cases in China, most of them are completed with the support of foreign theory and technology under the guidance of foreign experts. In order to accelerate the development of passive architecture in the Yangtze River Delta region, local governments and enterprises must introduce more professional and technical personnel to study the theory and technology, and cultivate more local professional and technical practitioners through the introduction of talents. Secondly, we speed up the development of energy-efficient design standards for passive buildings in all provinces and cities in the Yangtze River Delta region. Under the guidance of codes and standards, optimizing the energy-saving performance of key parts such as doors and windows, summarizing the key technologies of each link and improving the energy efficiency of passive buildings so as to guide cities in the Yangtze River Delta region to take the lead in implementing local standards higher than the national standards.

In terms of building materials, we will jointly develop regional industrial chains to realize localized building materials self-production and self-sufficiency. At present, China's production of doors and Windows, glass spacers, hardware and other material accessories cannot meet the high-performance requirements of passive buildings. Researchers need to study foreign passive building materials to make the quality of domestic products meet the use standards. Local materials with a complete industrial chain of independent production of building materials can not only save transportation and material costs, but also greatly reduce the total cost of passive buildings. 
In terms of policies, regional governments should jointly establish market-based mechanisms for energy conservation and emission reduction, and improve fiscal and tax incentive policies. Government departments can increase the strength of preferential policies through tax exemptions, interest-discount loans, capital subsidies and other measures to actively encourage enterprises to build passive buildings. At the same time, the government should integrate consumers into the beneficiary group, and give them corresponding subsidies to purchase passive houses. The government and enterprises can enhance the publicity of passive buildings through various forms of communication activities. Only by letting consumers truly understand the advantages of passive buildings can the consumer group be constantly expanded. In addition, the environmental protection department should cooperate with the government departments to establish a system of paid use and trading of energy use rights, and impose certain penalties on enterprises that do not respond to the energy conservation policy.

\section{The conclusion}

In a word, the current national conditions determine that the Yangtze River Delta region is in the leading position in China's economic development. Vigorously developing passive buildings can not only improve energy efficiency, but also achieve sustainable development of the construction industry. In the long run, passive buildings can meet the needs of regional economic value enhancement, environmental friendliness and residents' satisfaction. As important participants, the government, enterprises and individuals should face the resistance of passive buildings in the development process of the Yangtze River Delta region scientifically and objectively, and jointly explore the planning scheme that meets the needs of the times and the regional integration development.

\section{Acknowledgment}

This work was supported by the Social Science Foundati on project of Jiangsu Province (20EYB005), the Science and Technology Project of Zhangjiagang City (201904).

\section{References}

1. 2019 China building energy consumption research report [J]. Building, 2020 (07): 30-39.

2. Yu Mingliang, Li Yushi, Chen Wenhao, Xue Yinmin. A study on the driving factors of energy consumption change in the Yangtze River Delta: Based on 1995-2016 data analysis [J]. Journal of Southeast University (Philosophy and Social Sciences Edition), 2020, 22(02): 69-79.

3. "Hamburg House" of 2010 Shanghai World Expo [J]. Residential Area,2011(01):90-93.

4. Zhu Kan, Liu Xiaojing, Xu Chao. Analysis on application of ultra-low energy consumption passive building technology in Jiangsu Province [J]. Building Energy Conservation, 2016, 44(10): 7578+92.

5. He Wanting. The superiority of passive house and its development prospect [J]. Science and Technology Innovation and Application, 2018(15): 50-51. 